\section{sciendo}

DOI: 10.2478/ncr-2018-0005

(C) Article authors. This is an open access article distributed under the Creative Commons Attribution-NonCommercial-NoDerivs licens. (http://creaticecommons.org/licenses/by.nc-nd/3.0/).

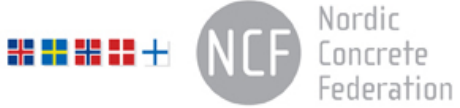

ISSN online 2545-2819

ISSN print $\quad 0800-6377$

Received: March 15, 2018

Revision received: May 7, 2018

Accepted: May 7, 2018

\title{
The Influence of Supplementary Cementitious Materials on Climate Impact of Concrete Structures Exposed to Chlorides
}

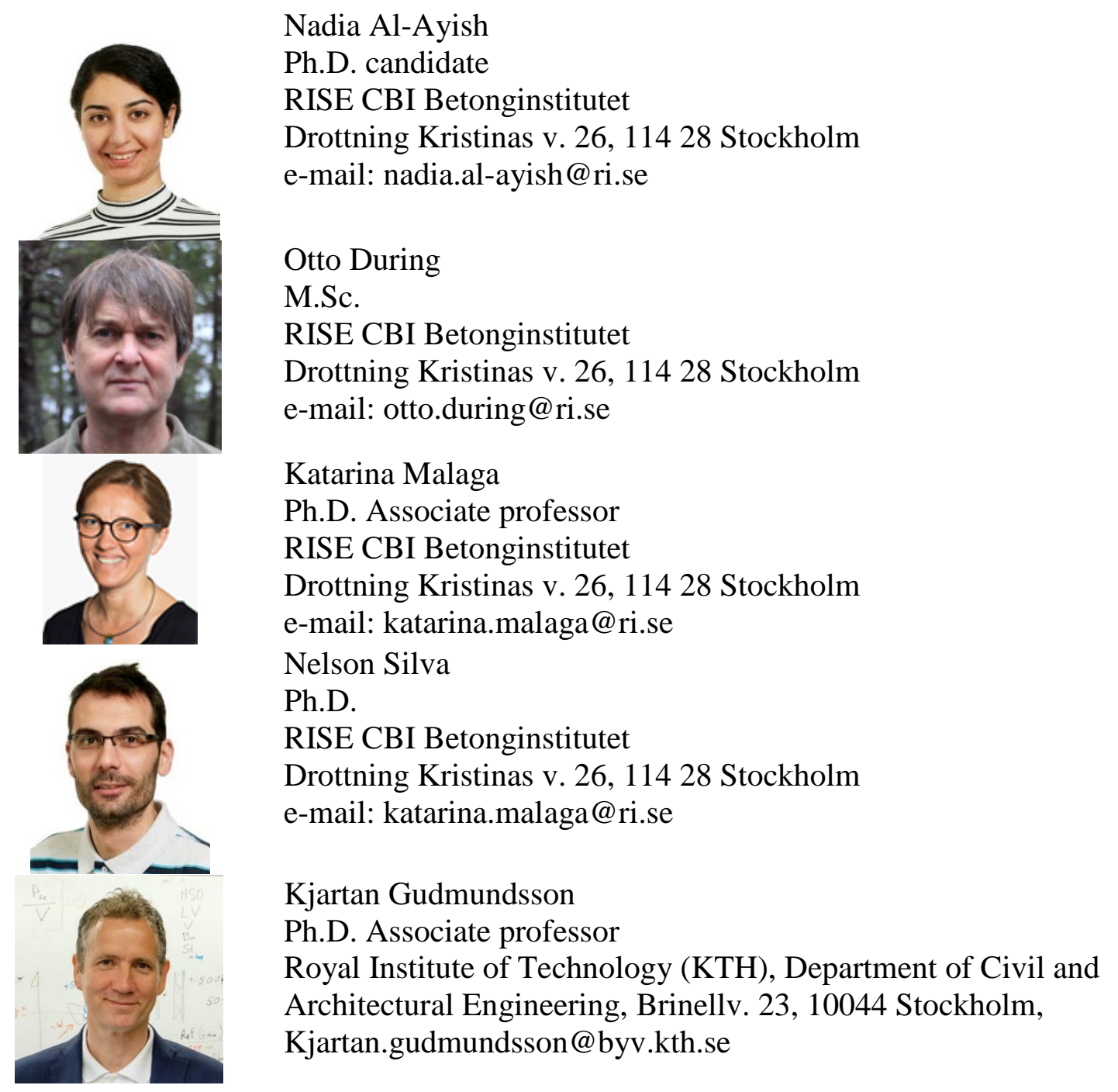

\section{ABSTRACT}

Addition of fly ash or GGBS in concrete has shown to increase the durability and thus the service life of concrete structures exposed to chlorides. Currently, the durability relies on 
regulations, which beside a minimum cover thickness also put constraint on amount and type of SCM in different environments. Swedish regulations do not, however, consider the actual durability of different binders. As a consequence, a LCA might be misleading. This paper investigates the climate impact of concrete with SCM in chloride environment. Current prescriptive design approach is compared with a performance based service life approach and applied to bridge parts.

Key words: chloride induced corrosion, Supplementary Cementitious Materials (SCM), climate impact, bridge, service life, LCA, concrete.

\section{INTRODUCTION}

The Swedish Transport Administration (STA) has identified a need to reduce greenhouse gases from infrastructures at a life-cycle perspective. In order to reduce these emissions STA has set a vision to reduce the climate impact of infrastructures by $15 \%$ until 2020, $30 \%$ until 2025 and zero emissions by 2050, compared to levels from 2015. For this reason STA has since 2016 set a demand that all infrastructure projects with an investment cost above 50 million SEK (approximately 5 million EUR) have to declare their climate impact [1]. Since concrete is the most common material used in bridges, efforts to reduce its climate impact will have a big effect on the overall reduction potential of the infrastructure [2].

There are different ways to reduce the climate impact of concrete structures. One way is to use the resources more efficiently by reducing the total clinker content in the concrete mix. This can be achieved for example by replacing part of the Portland cement (CEM I) with supplementary cementitious materials (SCM) from industrial waste products such as fly ash (FA) and groundgranulated blast furnace slag (GGBS). Another way to reduce the climate impact is by increasing the durability of the structure and thereby extending the service life and reducing the need for repair and replacement. Müller et al. [3] propose that the sustainability potential of a concrete structure should be defined as the relationship between the lifetime performance and the environmental impact. According to this definition the authors suggest three approaches to enhance the sustainability: 1) lowering the environmental impact of the concrete mix; 2) improving the concrete performance, i.e. reduction of cross-section of members through high load bearing capacity and 3) by extending the life span of the material and the structure. By reducing the need for repair and replacement there can be a significant reduction in environmental impact over the life span of a construction.

A bridge part that is frequently maintained and repaired is the edge beam. It is exposed to harsh conditions such as freezing and as a consequence also to chlorides due to the de-icing salts. According to a study by Racutanu the edge beam system is one of the bridge parts that gets damaged the most and stands for $33 \%$ of all damages noted in a large sample of Swedish concrete bridges [4]. Based on statistical data, the average age before replacing an edge beam is 45 years [5]. According to this research the time before replacement depends on the location where an edge beam in heavy traffic is replaced more frequently than in non-heavy traffic. This is also due to use of de-icing salts. Moreover, a study by Safi found that the life cycle measures (LCM) applied to an edge beam are: repair every 20 years, replacement every 60 years and impregnation every 20 years [6]. According to Veganzones et al. [7], except for high LCM costs, repair and replacement of bridge edge beams also cause user and societal costs due to traffic disturbance. 
One of the main deterioration problems in reinforced concrete (RC) structures is chloride induced corrosion [8]. In order to protect the reinforcement from corrosion and obtain a certain service life a minimum concrete cover thickness is needed. At present, this cover thickness is mainly based on current regulations in Sweden that do not differentiate between cement types and concrete compositions. A study on chloride ingress in Swedish conditions by Tang and Löfgren [9] concludes, however, that this cover thickness should also depend on the addition of SCM. The aim of this study is therefore to evaluate the global warming potential (GWP) of RC structures exposed to chlorides considering the durability of SCMs. Although researches have shown the link between environmental impact and durability there is still a lack of LCA studies that include the actual performance of reinforced concrete structures with different mix designs. This study evaluates the climate impact of mix designs with various amounts of SCM based on their influence on concrete performance. The mix designs are applied on two bridge parts, a bridge edge beam, which is exposed to de-icing salt and a bridge pier, which is exposed to constant chloride diffusion. The performance based approach is based on recent research [9] and compared with current prescriptive approach. Chloride induced corrosion is the only deterioration mechanism that is considered in this study.

\section{DURABILITY OF CHLORIDE EXPOSED CONCRETE WITH SCM}

Durability of steel reinforced concrete depends on several factors such as concrete properties, environmental exposure, ageing of concrete and steel quality. Steel reinforcement in concrete is protected from corrosion by a passivating film that is created due to the high alkalinity of the pore solution. When concrete carbonates, the $\mathrm{pH}$ in the pore solution drops, activating the corrosion process. However, a $\mathrm{pH}$ reduction is not the only corrosion inducing process. When chloride ions penetrate the concrete and reach a certain concentration at the depth of the reinforcement, a so called threshold value, an electrochemical process starts the corrosion of steel, even without a drop in $\mathrm{pH}$. There are three mechanisms leading to chloride induced corrosion [10]; 1) The chloride ions in the electrolyte may penetrate through the passive film to the steel surface due to the high potential difference across the film. 2) The film may break due to discontinuities in the film. 3) And lastly, adsorption of ions to the film may lead to progressive thinning.

When chloride ions diffuse through pores into the concrete, some of the ions will be bound chemically to the aluminate phase in the cement [11], some will be physically bound to the pore walls [12] and some will be free in the pore solution. The reaction of steel is dependent on the concentration of free chloride ions. However, when defining a chloride threshold value it is difficult to measure the free ions only and a total chloride content is therefore used. The resistance of concrete to chloride diffusion depends on several factors of which one is the addition of SCM. In previous times addition of fly ash or ground-granulated blast furnace slag (GGBS) has been linked to an increased risk of corrosion due to a lower alkalinity in the pore solution $[13,14]$. More recent studies, however, have shown that fly ash and GGBS contain a higher amount of alumina which leads to an increased chemical binding of chlorides [15,11], thus increasing chloride threshold. Additionally, a denser microstructure in fly ash and GGBS incorporated concrete has also been observed which means that the diffusion coefficient might also be lower [16]. A literature study by Shi et al. [17] concluded that concrete with SCMs has an overall improved resistance to chloride ingress. 
The chloride threshold is an important parameter regarding service life modelling. There is however a large scatter in the literature. According to Angst et al. [15] the scatter of the chloride threshold value is smaller for field studies.

\section{3.}

\section{SERVICE LIFE PREDICTION}

Sustainability of a structure is greatly dependent on the technical performance under the designed service life. The more durable the structure is the lower are the repair costs and the environmental impact. The difficulty in a LCA model is the service life prediction. There is statistical data on repair and maintenance, but they do not consider the durability of different concrete mix designs and binders. The consequence is therefore a significant gap when designing a sustainable concrete structure.

The design service life should include an anticipated maintenance, but without the necessity of a major repair. ISO 16204 defines 4 methods with different levels of sophistication to verify the design service life, namely: full probabilistic (DuraCrete model in Fib bulletin 34) [18], partial factor, deemed-to-satisfy and avoidance of deterioration [19]. This paper compares a performance based service life model for chloride ingress with a prescriptive service life approach.

\subsection{Today's prescriptive service life design}

In a prescriptive or deemed-to satisfy service life approach the service life is designed through constrains on minimum cover thickness and on concrete properties in different environmental exposures such as water to cement ratio, clinker content and amount of SCM content in binder [20]. The concrete cover does not, however, vary with type of binder. It only depends on the water to cement $(\mathrm{w} / \mathrm{c})$ ratio.

Table 1 demonstrates the allowable limits for reinforced concrete in different chloride environments in order to reach a service life of 100 years as defined in the Swedish application of the European construction standards, EKS 10 [21,22].

Table 1 - Allowable limits for the chloride exposure classes used in this research. The material properties are from SS EN 137003 [21] while the cover thicknesses are from EKS 10 [22].

\begin{tabular}{cccc}
\hline & $\begin{array}{c}\text { XS2 } \\
\text { (submerged in sea) }\end{array}$ & $\begin{array}{c}\text { XD3 } \\
\text { (de-icing salt) }\end{array}$ & $\begin{array}{c}\text { XF4 } \\
\text { (frost) }\end{array}$ \\
\hline W/C(eq) [-] & 0.45 & 0.40 & 0.45 \\
Max addition [\% of binder] & & & \\
FA & 35 & 35 & 20 \\
GGBS & 65 & 35 & \\
Concrete cover for: & & & NA \\
W/C 0.4, 100yr [mm] $]^{1}$ & 45 & 45 & NA \\
W/C 0.45, 100yr [mm]
\end{tabular}

${ }^{1}$ Excluding $10 \mathrm{~mm}$ tolerance 
There are several models for calculating the chloride ingress in reinforced concrete structures. Some models are: the simple ERFC model, the Mejlbro-Poulsen's model, the DuraCrete model, ACI Life 365 and the ClinConc model [9]. The first four models use the total chloride content as the main driving force in the transport function while the ClinConc model takes into account the free chlorides in the pore solution. What the models have in common is the assumption of a crack-free concrete and that they are based on Fick's $2^{\text {nd }}$ law of diffusion.

The best curve fitted model is, according to Tang et al. [23], the ClinConc model which considers the free chlorides in the pore solution. Tang and Löfgren [9] used this model to evaluate the durability of concrete with SCM exposed to chlorides. The chloride ingress was modeled for marine and road environments with a service life of 100 years and chloride threshold at $1.0 \%$ and $0.4 \%$ of mass of binder respectively. Field data from concrete exposed to Swedish seawater under a period of 20 years were used for validating the study. Tang and Löfgren concluded that an addition of FA and GGBS in concrete improves the resistance to chloride ingress and that current prescribed cover thicknesses are not enough for concrete without SCM. The authors proposed therefore modified concrete cover thicknesses which also consider the addition of FA and GGBS. Table 2 shows the proposed cover thicknesses for the environmental classes XS2 and XD3 and water to binder (w/b) ratios 0.40 and 0.45 .

Table 2 - Suggested concrete cover thicknesses (in $\mathrm{mm}$ ) for chloride environment [9].

\begin{tabular}{lccccc}
\hline & CEM I & CEM II/A-S & $\begin{array}{c}\text { CEM II/A-V } \\
\text { or } \\
\text { CEM II/B-V }\end{array}$ & CEM II/B-S & CEM III/A \\
\hline XS2 (east coast ${ }^{1}$ ) & 90 & 60 & 60 & 60 & 50 \\
w/b 0.45 & 80 & 50 & 45 & 50 & 45 \\
w/b 0.40 & 70 & 45 & 45 & 45 & 45 \\
XD3 & & & & \\
w/b 0.40 & & & & & \\
\hline
\end{tabular}

${ }^{1}$ Refers to the east coast of Sweden which has a chloride concentration of about $0.4 \%$ by mass of seawater.

To evaluate the sensitivity of the cover thicknesses Tang and Löfgren [9] included the uncertainties of the input parameters; chloride threshold, diffusion coefficient at 6 months, surface chloride content and temperature. The results showed that a $10 \%$ variation of the input parameters resulted in a 3 to $5 \%$ variation of the determined cover thicknesses independent of type of concrete. The chloride threshold value was shown to have the lowest influence on the cover thickness (approximately $3 \%$ ).

\section{LCA OF RC STRUCTURES IN CHLORIDE ENVIRONMENT - A CASE STUDY}

The environmental effect of using todays' prescriptive cover thicknesses is investigated. The cover thicknesses in Table 1 are compared to the performance based cover thicknesses in Table 2 for concrete mix designs with and without SCM and two w/b ratios.

The following aspects are investigated in the analysis: 
- The effect of SCM on service life and material consumption during a period of 100 years. To what extend does the improved durability of concrete with SCM reduce the GWP?

- The effect of introducing a performance based cover thickness on GWP. What would a difference in cover thickness mean?

- The difference in w/b ratio on GWP of RC structure. Concrete with higher w/b ratio has a lower durability and needs therefore a thicker concrete cover but has on the other hand lower clinker content. Is it better for the climate to use concrete with lower w/b ratio or higher?

- The consequences of using today’s prescribed cover thicknesses.

\subsection{Case study}

A bridge edge beam and a bridge pier have been chosen as case studies for the LCA. The bridge edge beam is a sensitive part of a bridge in terms of damages and has a high repair cost and environmental impact due to traffic disturbances. In this case study the edge beam is part of a road bridge and is exposed to de-icing salt which means that it is subjected to chlorides through spraying. This is exposure class XD3 according to EN 206 and limits the w/c ratio to maximum 0.40 .

A bridge pier has a load carrying function and is subjected to different chloride exposures which are related to the atmospheric zone, tidal/splash zone and the submerged zone. From a 20 year field study on chloride ingress it has been observed that the submerged zone is the most severe case [24]. For that reason the submerged zone is chosen for the analysis in this case study. The influence of using different w/c ratios is investigated for the pier only as XD3 does not allow a $\mathrm{w} / \mathrm{b}$ ratio of 0.45 . The question is if it is more environmentally friendly to have a concrete with a higher w/c ratio and thus lower clinker content or more beneficial to have a lower w/c ratio where the concrete has a denser structure.

Both case studies are fictive and not related to a specific type of bridge which means that the maintenance will be unknown. Instead a theoretical figure for repair and replacement is used. A cast in situ concrete is assumed for both cases. The reference dimensions for both cases are shown in Table 3 and are based on concrete cover thicknesses according to EKS 10. An adequate distance between piers is assumed.

Table 3 - Specifications of the reference cases.

\begin{tabular}{llllll}
\hline Reference case & w/c ratio & $\begin{array}{l}\text { Cover } \\
\text { thickness }\end{array}$ & Cross section & Length & Reinforcement \\
\hline $\begin{array}{l}\text { Bridge edge } \\
\text { beam }\end{array}$ & 0.40 & $45 \mathrm{~mm}$ & $\begin{array}{l}\text { Rectangular } 0.5 \\
\text { m x } 0.5 \mathrm{~m}\end{array}$ & $10 \mathrm{~m}$ & 4 weight-\% \\
Bridge pier & 0.40 & $45 \mathrm{~mm}$ & $\begin{array}{l}\text { Circular } 1 \mathrm{~m} \\
\text { diameter }\end{array}$ & $6 \mathrm{~m}$ & $\begin{array}{l}4 \% \text { of cross } \\
\text { sectional area }\end{array}$ \\
\hline
\end{tabular}

When the concrete cover thickness is varied it is assumed that the reinforcement position and amount are constant. This means that there will be a change in cross sectional area and thus concrete volume which could be the case when the amount of reinforcement is already optimized and moving the reinforcement inward is not an option. Additionally, it is also a 
conservative way of performing the LCA because it adds an extra GWP to the performance based cover thicknesses.

\subsection{Concrete mix design}

In this study 8 different concrete mix designs, which were developed within a STA project, have been evaluated (Table 4). The mix designs consist of 4 types of binders with varying amount of FA and GGBS and two w/b ratios. No efficiency factor (i.e., a factor $=1$ ) was used in the concrete mixes with SCM which means that w/b ratio is equal to w/c ratio. Mixes with a binder that contains 20 weight-\% SCM or less meets the requirements for frost resistance according to SS 137003, the Swedish application of EN 206 [22]. The concrete mixes with $29 \%$ GGBS exceeds the limit but is still included due to a recent study which shows that a GGBS content of up to $40 \%$ of binder may be acceptable with respect to the salt-frost scaling resistance [25]. The mixes also contain superplastisizers and air-entrainer which are not shown in Table 4. This is due to the small amounts used which are assumed to have only a negligible effect on the outcome of the environmental impact.

Table 4 - Mix design of the concretes used in this analysis.

\begin{tabular}{lcccccc}
\hline \multicolumn{1}{c}{ Mix ID } & w/b & $\begin{array}{c}\text { OPC } \\
{\left[\mathbf{k g} / \mathbf{m}^{3}\right]}\end{array}$ & $\begin{array}{c}\text { FA } \\
{\left[\mathbf{k g} / \mathbf{m}^{3}\right]}\end{array}$ & $\begin{array}{c}\text { GGBS } \\
{\left[\mathbf{k g} / \mathbf{m}^{3}\right]}\end{array}$ & $\begin{array}{c}\text { Aggregates, } \\
\text { crushed } \\
{\left[\mathbf{k g} / \mathbf{m}^{3}\right]}\end{array}$ & $\begin{array}{c}\text { Aggregates, } \\
\text { natural } \\
{\left[\mathbf{k g} / \mathbf{m}^{3}\right]}\end{array}$ \\
\hline CEM I 0.40 & 0.40 & 425 & & & 846 & 864 \\
16\% FA 0.40 & 0.40 & 353 & 69 & & 844 & 863 \\
20\% GGBS 0.40 & 0.40 & 340 & & 85 & 842 & 861 \\
29\% GGBS 0.40 & 0.40 & 302 & & 123 & 836 & 854 \\
CEM I 0.45 & 0.45 & 400 & & & 846 & 864 \\
16\% FA 0.45 & 0.45 & 336 & 64 & & 842 & 861 \\
20\% GGBS 0.45 & 0.45 & 320 & & 80 & 841 & 859 \\
29\% GGBS 0.45 & 0.45 & 284 & & 116 & 839 & 858 \\
\hline
\end{tabular}

\section{3}

\section{LCA method}

In order to calculate the GWP of the aforementioned concrete structures a LCA method in accordance with EN 15804 [26] is applied. EN 15804 provides core product category rules for construction products and services and also the means for developing a Type III environmental declaration. The GWP is calculated by using the method by IPCC (Intergovernmental Panel on Climate Change) 2013 GWP100a.

The LCA includes the following life-cycle stages: 
- Production stage (module A1-A3). It includes raw material extraction, transport of raw material to factory and manufacturing)

- Replacement (module B4). With a system boundary of 100 years.

The service life of the edge beam and pier is included through the replacement stage. For example, if a structure has a service life of 80 years and the system boundary is 100 years, then it would mean that the structure needs to be replaced theoretically 0.25 times to reach those 100 years. In reality, not all structures with a specific service life are repaired at the same time. Some might be repaired earlier and some might be repaired later. This theoretical number represents an average value.

The functional units for the cases are:

1. 1 length meter bridge edge beam with a service life of 100 years. Exposed to de-icing salt.

2. 1 length meter bridge pier with a service life of 100 years. Exposed to marine environment with a $0.4 \%$ chloride concentration.

It should be noted that the LCA does not take into account the construction and maintenance activities at site such as machinery. It only considers the material use.

Life-cycle inventory data were mainly gathered from environmental product declarations (EPD) for the Swedish market and the LCA database ecoinvent version 3 [27]. An inventory of materials and energy is described in Table 5.

Regarding waste products and secondary materials, they are considered to have no environmental burden allocated from the main product unless they have a contribution to the overall revenue that is higher than $1 \%$. An economic evaluation was performed which showed that the revenue of fly ash and the slag leaving the industrial process can be considered to be very low according to EN 15804 [26]. Hence there is no environmental burden allocated to fly ash and slag waste. However, while fly ash can be utilized directly in the concrete mix without further processing GGBS needs to be grinded and dried before applied. This adds an extra environmental burden to GGBS. Information about GGBS processing was delivered through personal contact with Merox AB [28].

The required energy at the factory is based on information from a Thomas Concrete Group factory in Sweden and has an energy consumption of $18 \mathrm{kWh} / \mathrm{m}^{3}$ electricity and $15 \mathrm{kWh} / \mathrm{m}^{3}$ district heating [29]. The district heating is based on a Swedish mix from Svensk fjärrvärme during the reference year 2014 [30] where the fuels were gathered from ecoinvent v.3. All materials, except for the reinforcement, are transported from real manufacturing places to a concrete factory located in Stockholm. The reinforcement is instead transported directly to the construction site. Data for transport were gathered from Network for Transport Measures (NTM) [31]. 
Nordic Concrete Research - Publ. No. NCR 58 - ISSUE 1 / 2018 - Article 5, pp. 77-93

Table 5 - GWP of materials and energy sources.

\begin{tabular}{lccl}
\hline Resource & Unit & GWP [kg CO $\mathbf{~}_{2}$-eq] & Reference \\
\hline OPC & 1 ton & 678 & $\begin{array}{l}\text { EPD-HCG-20140186-CAD1- } \\
\text { FA }\end{array}$ \\
1 ton & 0 & \\
GGBS & 1 ton & 88 & {$[28]$} \\
Water & 1 ton & 0.28 & Ecoinvent v.3 \\
Aggregates, crushed & 1 ton & 2.4 & Ecoinvent v.3 ${ }^{1}$ \\
Aggregates, natural & 1 ton & 1.7 & Ecoinvent v.3 \\
$\begin{array}{l}\text { Carbon steel } \\
\text { reinforcement }\end{array}$ & 1 ton & 370 & EPD S-P-00305 \\
District heating & $1 \mathrm{kWh}$ & 0.092 & {$[30]$} \\
Swedish electricity mix & $1 \mathrm{kWh}$ & 0.056 & Ecoinvent v.3
\end{tabular}

${ }^{1}$ Modified for Swedish conditions.

\subsection{Service life modelling}

According to Tang and Löfgren [9] the prescribed cover thicknesses for a service life of 100 years are not always sufficient and need therefore to be updated. In order to calculate the service life of reinforced concrete designed with current Swedish regulations, the ERFC (error function complement) model for chloride diffusion in an infinite half-space was used. The influence of concrete ageing is excluded in the model which is a conservative way of calculating the service life.

For the reason that the chloride profile is fixed for each concrete mix due to the same environmental exposures and chloride diffusion properties then the service life will only depend on the relation between two cover thicknesses. This is expressed in equation (1). The service life can be calculated by using the figures of Tang and Löfgren [9], also expressed in Table 2, as a reference which the calculated service life relates to. For example, if a reinforced concrete structure of a certain mix has a cover thickness of $45 \mathrm{~mm}$ and it is assumed that the corresponding service life is 100 years then a cover thickness of $40 \mathrm{~mm}$ will result in a service life of t years. In this case a $45 \mathrm{~mm}$ cover thickness and a service life of 100 years will be the reference.

$$
t=t_{r e f} \cdot\left(\frac{x}{x_{r e f}}\right)^{2}
$$

Where:

$\mathrm{t}=$ service life of concrete with $\mathrm{x}$ cover thickness [year]

$t_{\text {ref }}=$ service life of reference concrete with $x_{\text {ref }}$ cover thickness [year]

$\mathrm{x}=$ cover thickness of concrete [mm]

$\mathrm{x}_{\mathrm{ref}}=$ cover thickness of reference concrete [mm] 


\subsection{Impact of concrete mix design}

It is well known that the climate impact of a concrete mix is highly dependent on the clinker content. When a part of the clinker is replaced with FA or GGBS the climate impact is expected to decrease accordingly. Figure 1 shows the GWP of the concrete mix designs used in this study divided into the life cycle stages: material production, transport to factory and production at factory. It can be noted that a clinker replacement with $16 \%$ FA results in a $15 \%$ reduction of GWP compared to CEM I concrete for both w/b ratios. An increase in w/b ratio results in an approximately $6 \%$ decrease in GWP. Transport to factory and production at factory has a slight impact on the GWP.

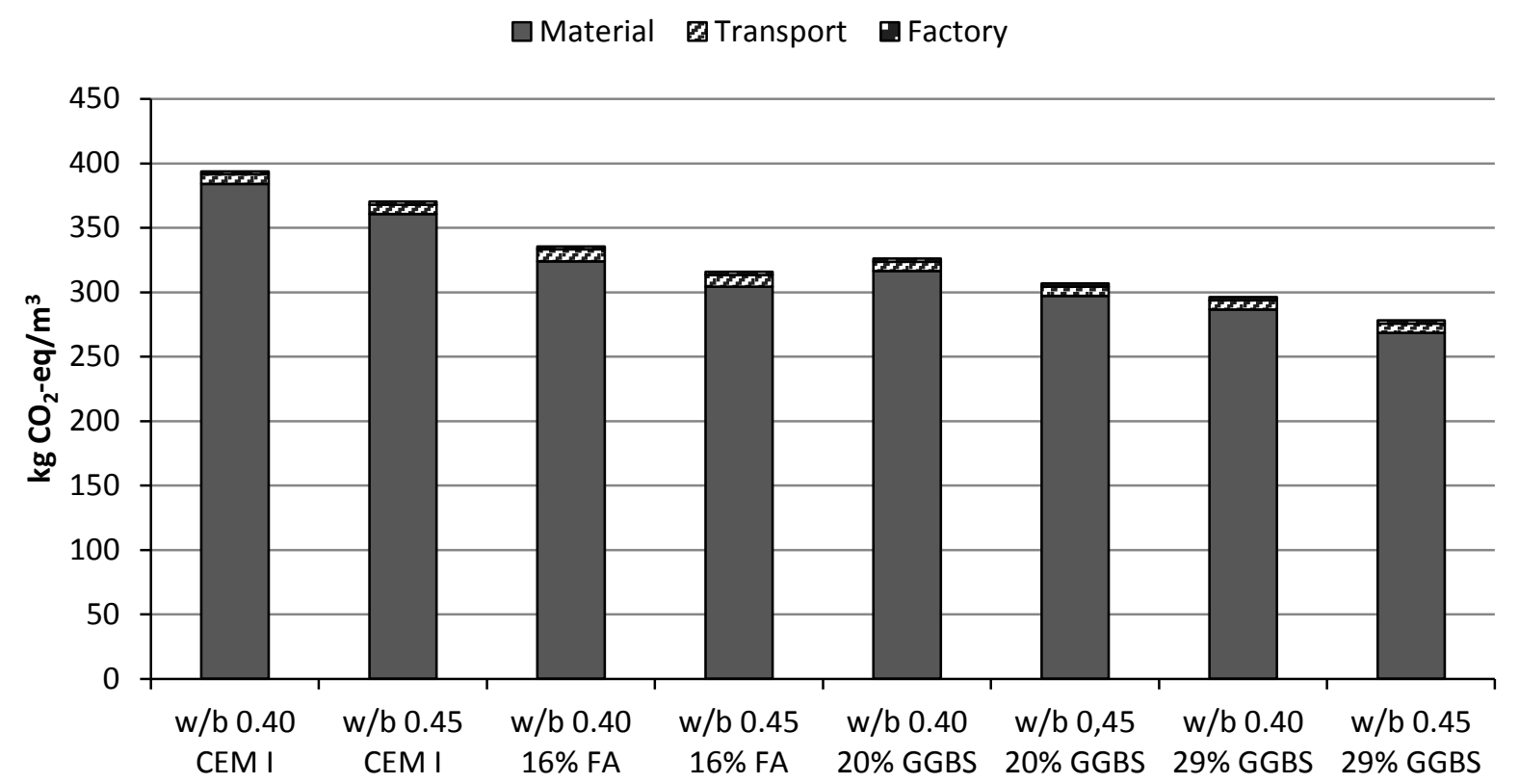

Figure $1-G W P$ of $1 \mathrm{~m}^{3}$ of concrete mixes used in this research, divided into three life cycle stages

\section{Impact of edge beam and pier during production stage}

When the concrete mixes are applied to a reinforced bridge edge beam with a cover thickness according to today's Swedish regulations the result show a decrease in GWP of $14 \%, 16 \%$ and $23 \%$ for the concrete mixes with $16 \%$ FA, $20 \%$ GGBS and $29 \%$ GGBS respectively, compared with CEM I (Figure 2). These greenhouse gases are emitted during the production stage of the concrete and reinforcement. For the proposed performance based concrete cover thicknesses the effect of lower chloride ingress due to addition of SCM may be visualized. In order to have a sufficient cover thickness which enables a service life of 100 years the cover needs to be increased by $25 \mathrm{~mm}$. This leads, in this case, to an increase in volume which in turn results in an increase in GWP by $19 \%$. According to the performance based approach an addition of $16 \%$ FA have the potential to lower the GWP by $27 \%$, which is a big impact. 
口CT EKS $10 \quad$ Q $C$ CT Tang \& Löfgren 2016

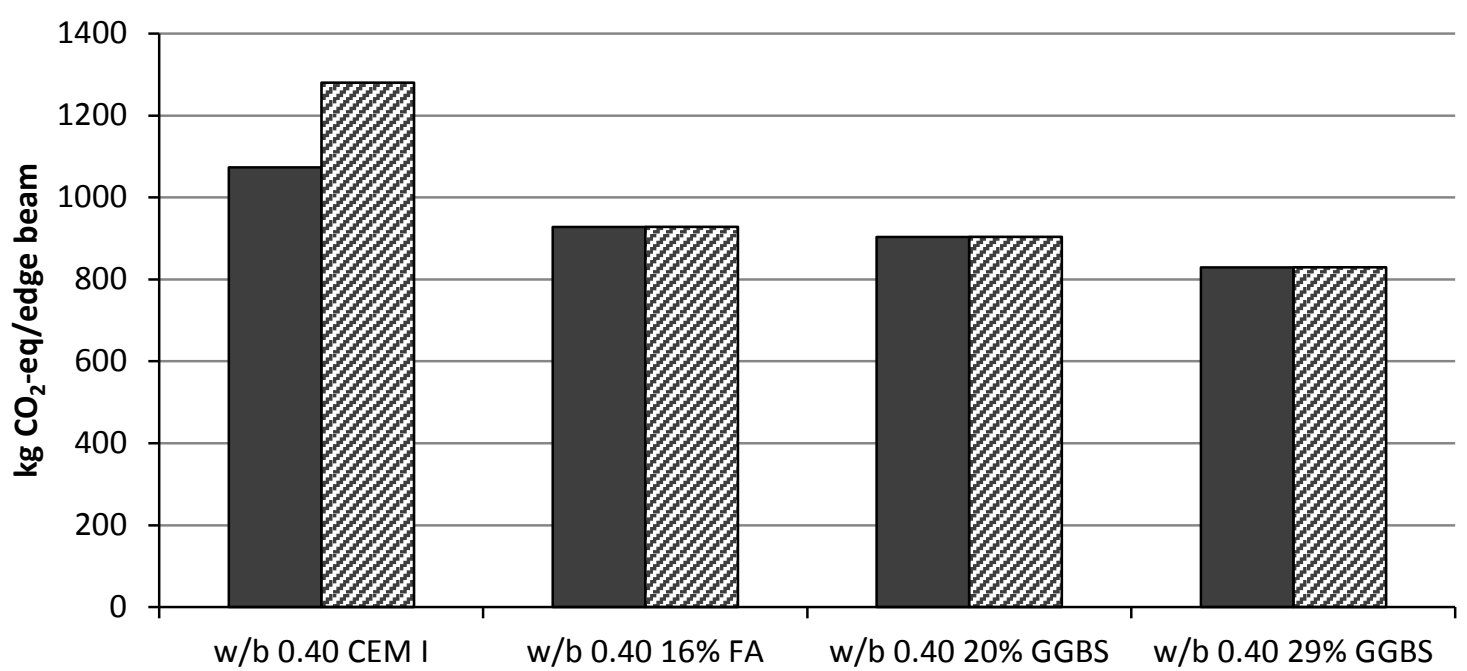

Figure 2 - GWP from production of one bridge edge beam.

Concerning the bridge pier, except for an addition of SCM the effect of w/b ratio on the GWP has also been investigated. The results revealed that there is not a significant difference between $\mathrm{w} / \mathrm{b}$ ratios as the extra cover thickness compensate for a reduction in clinker content (Figure 3). Still there is a notable difference between CEM I and concrete with SCM.

口CT EKS $10 \quad$ 口CT Tang \& Löfgren 2016

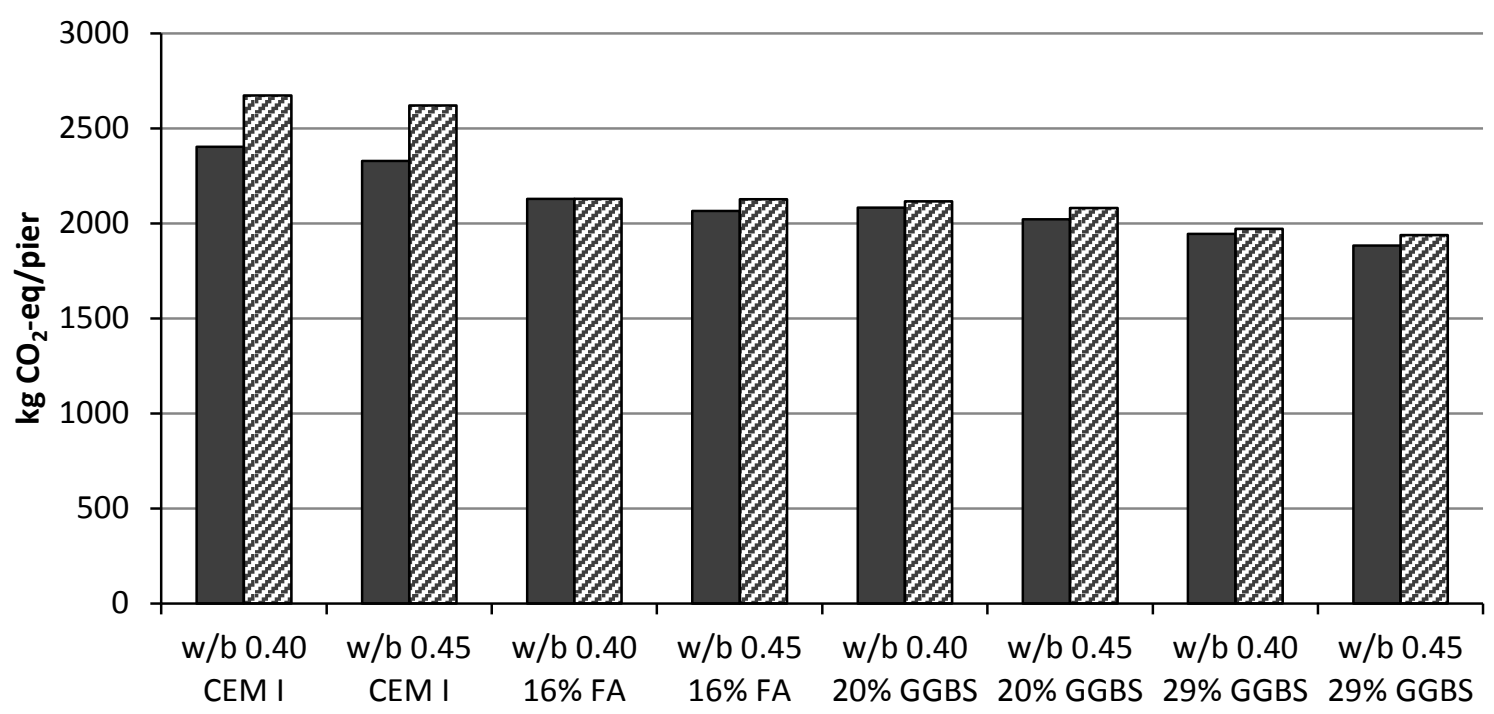

Figure 3 - GWP from production of one bridge pier.

The GWP of the reinforcement is $7 \%$ of the total GWP for the edge beam and $20 \%$ for the pier.

\subsection{Impact of edge beam and pier including service life}

The cover thicknesses according to Tang and Löfgren [9] represent a service life of 100 years. The cover thicknesses according to standard are fixed and do not vary with binder type which 
leads to a variation in service life. Table 7 shows the calculated service lives for a fixed concrete cover according to the standard using Eq. (1).

Table 7 - Calculated service life of edge beam and pier with a cover thickness according to EKS 10 [22].

\begin{tabular}{llllll}
\hline & $\begin{array}{l}\text { Cover } \\
\text { thickness }\end{array}$ & $\begin{array}{l}\text { Mix - } \\
\text { CEM I } \\
\text { [years] }\end{array}$ & $\begin{array}{l}\text { Mix - } \\
\text { 16\%FA } \\
\text { [years] }\end{array}$ & $\begin{array}{l}\text { Mix - } \\
\text { 20\%GGBS } \\
\text { [years] }\end{array}$ & $\begin{array}{l}\text { Mix - } \\
\text { 29\%GGBS } \\
\text { [years] }\end{array}$ \\
\hline Edge beam w/b 0.40 & $45 \mathrm{~mm}$ & 41 & 100 & 100 & 100 \\
Pier w/b 0.40 & $45 \mathrm{~mm}$ & 32 & 100 & 81 & 81 \\
Pier w/b 0.45 & $50 \mathrm{~mm}$ & 31 & 69 & 69 & 69 \\
\hline
\end{tabular}

When the service life and hence the need of repair and replacement is included in the LCA the effect of the chloride ingress becomes clearer. If a fixed cover thickness is used for all binder types then the results reveal that there will be a dramatic increase in GWP for concrete with CEM I for both exposure classes due to the better durability performance of concrete with SCM. For the bridge edge beam with CEM I this would mean a replacement of 1.4 times during a period of 100 years which equals a total GWP of $2597 \mathrm{~kg} \mathrm{CO}_{2}$-eq (Figure 4). An addition of fly ash could in this case reduce both $\mathrm{CO}_{2}$ emissions and costs. Regarding the pier the results show an even bigger difference with a replacement ratio of 1.7 times which equals a total GWP of $7598 \mathrm{~kg} \mathrm{CO}$-eq (Figure 5). However, a bridge pier is rarely replaced and not all of the reinforcement is replaced either which could mean a lower GWP in reality. Nevertheless, there is still a significant difference in GWP for concrete with and without SCM.

If a w/b of 0.45 was to be used instead of a w/b of 0.40 when designing a pier according to EKS 10 [22] then this would lead to a reduced service life for all binder types. A small increase in cover thickness has a big reduction in GWP. When a performance based cover thickness is applied then there is not a significant difference between w/b ratios 0.40 and 0.45 .

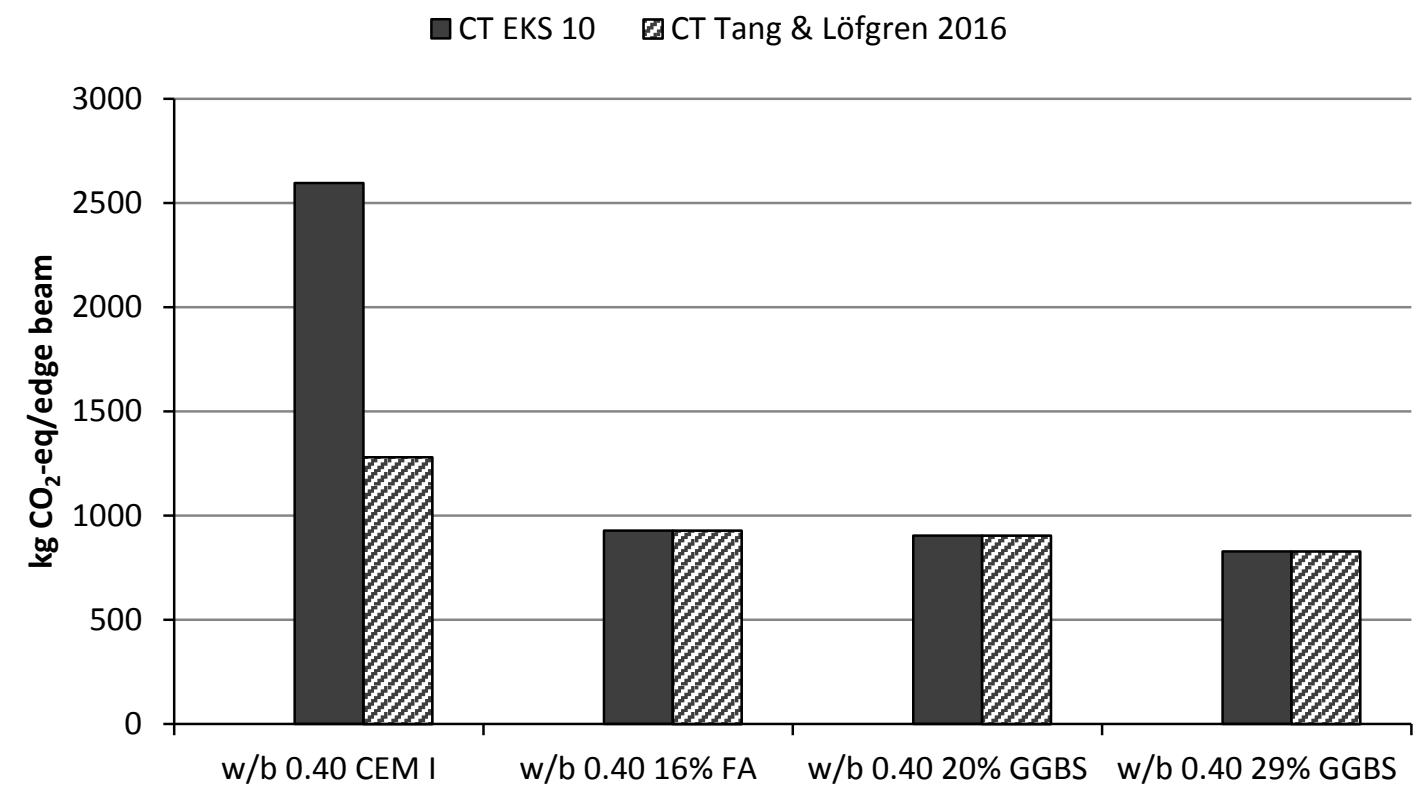

Figure 4 - GWP from production and replacement of bridge edge beam. 


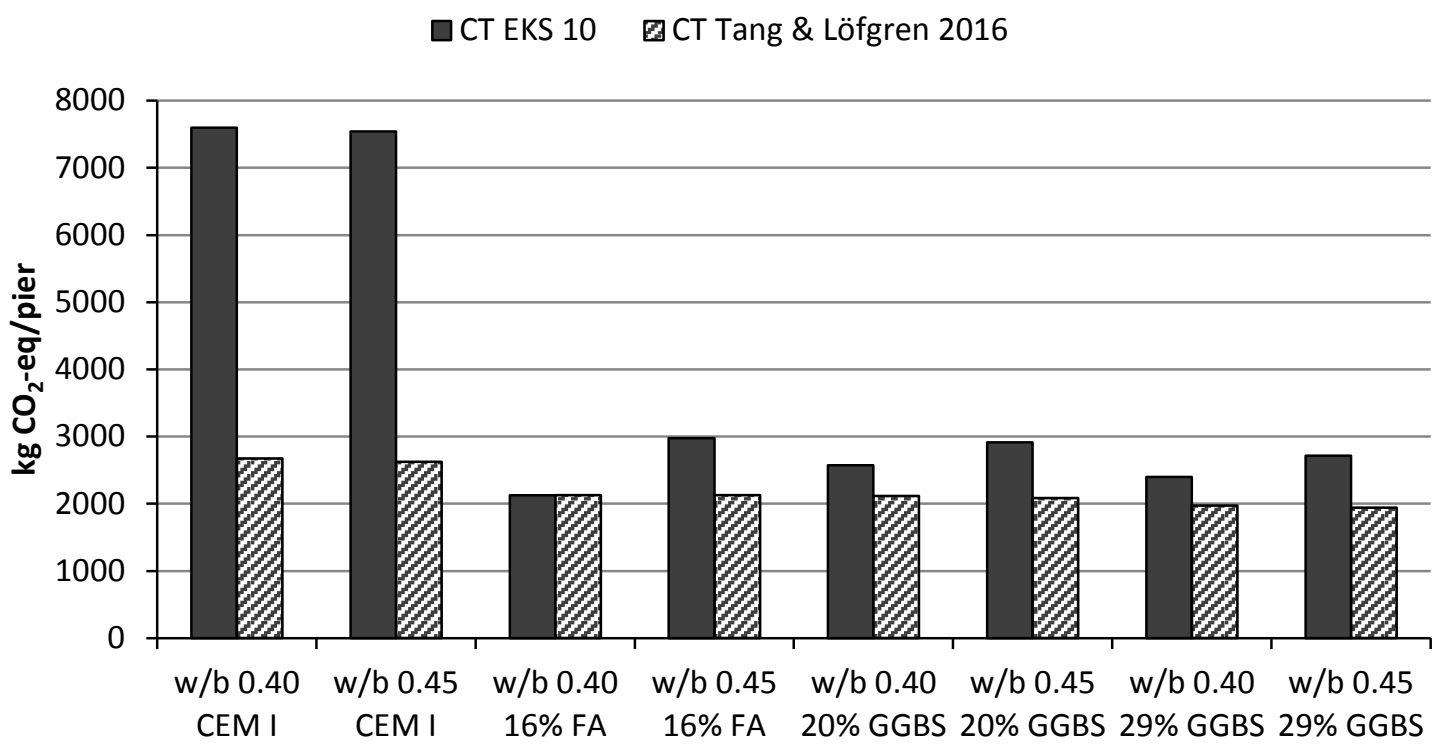

Figure 5 - GWP from production and replacement of bridge pier.

\section{4}

Influence of SCM on service life design and $\mathrm{CO}_{2}$

The results in this study show that an addition of FA and GGBS lowers the climate impact not only due to lower clinker content but also by increasing the durability properties of concrete exposed to chlorides. By adapting the cover thickness after type of binder major savings in GWP can be achieved. The relation between cover thickness, service life, binder type and GWP for a bridge pier with two dimensions, $0.5 \mathrm{~m}$ and $1 \mathrm{~m}$ in diameter, is expressed in Figure 6. Only the concrete has been taking into consideration. In this case where the reinforcement is fixed a GWP for a specific type of reinforcement can be added to the GWP for a total climate impact of the structure. The binder types which are analyzed in a performance based approach are CEM I and $16 \%$ FA for w/b 0.40 .

Figure 6 shows that when designing a pier to last a certain amount of years, a cover thickness and GWP will be obtained depending on binder type. For example would a service life of 100 years result in a cover thickness of $80 \mathrm{~mm}$ for CEM I and $45 \mathrm{~mm}$ for a binder with $16 \%$ FA. The GWP would then be $1.0 \mathrm{~kg} \mathrm{CO}$-eq/myear for CEM I and $0.66 \mathrm{~kg} \mathrm{CO}$-eq/myear for $16 \%$ FA, a $34 \%$ difference. The GWP can also be calculated the other way around by first choosing cover thickness. If a pier is designed to have a concrete cover of $50 \mathrm{~mm}$ then using a binder with $16 \%$ FA instead of CEM I would increase the service life by 80 years which is equal to a $72 \%$ decrease in GWP.

The cross-section area also has an influence on the GWP. The smaller the cross-section area is the greater will it be affected by the binder type and thus cover thickness. The reason is that the total relative volume change due to an increase or decrease in cover thickness will be greater. 


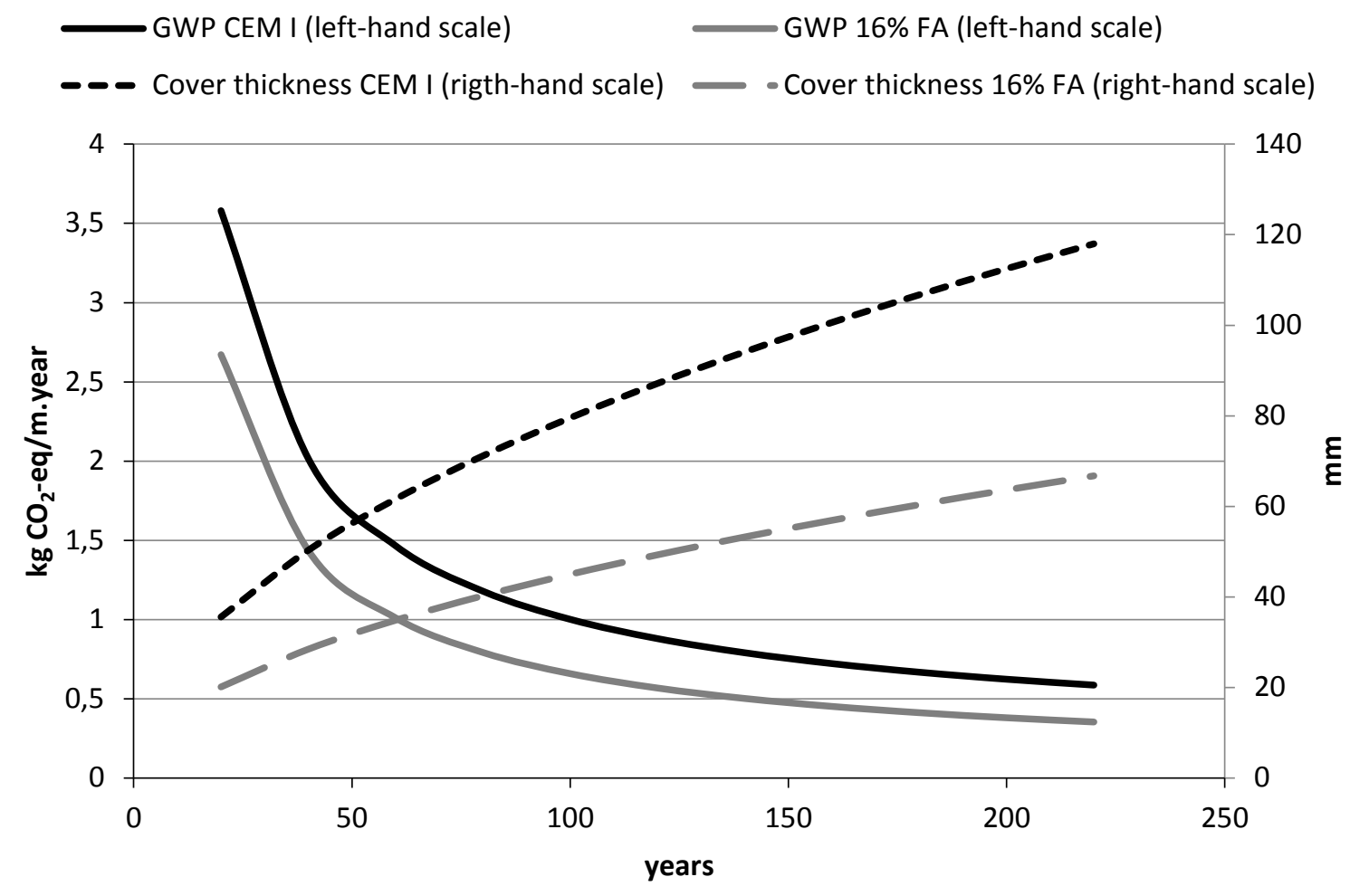

Figure 6 - Relation between GWP, service life, cover thickness and binder type.

6.

DISCUSSION

This study shows that there is a twofold effect of SCM on the GWP of reinforced concrete structures exposed to chlorides. Not only does it reduce the climate impact by lowering the clinker content but it also extends the service life through an improvement in durability. This reduces the demand for repair and replacement, thus saving resources through the whole life cycle.

The results showed that today's cover thicknesses are, for the most part, not adequate in order to reach a service life of 100 years. For an edge beam with CEM I and w/b 0.40 this would result in 1.4 replacements during the service life which is in line with today's maintenance of 1 replacement and 3 repairs. If, however, the cover thickness is instead increased from $45 \mathrm{~mm}$ to $70 \mathrm{~mm}$ or if fly ash is added then the need for repair would be dramatically reduced resulting in a lower GWP. A reduced maintenance does not only reduce the climate impact it also reduces user and societal costs significantly, especially for heavily trafficked road bridges.

For a submerged condition, XS2, an even bigger reduction in GWP can be made. The analysis also revealed that there is not a significant difference between $\mathrm{w} / \mathrm{b} 0.40$ and 0.45 . Nevertheless, this analysis investigates the effect of the concrete volume only, meaning that the reinforcement is fixed to a constant amount and location. Another approach is to also investigate the effect of the reinforcement by fixing the cross-section area.

Consequences of ignoring the durability in LCA are wrong assumptions for the service life and maintenance which result in misleading environmental impact results. Durability and service life should be included in the environmental optimization of reinforced concrete structures. 
Introducing a performance-based approach for service life design could help reducing the GWP as it could open up for usage of new binder types and concrete mix design.

To reduce the climate impact of concrete infrastructures it is suggested that a minimum amount of FA or GGBS is encouraged by STA for bridges exposed to chlorides. It would not only improve the durability but also the sustainability potential defined by Müller et al. [3] by all three approaches; lower GWP in mix design, reduction in concrete volume and increased service life.

\section{CONCLUSIONS AND FUTURE RESEARCH}

Based on the results of this study it can be concluded that there is a need to implement performance based cover thicknesses. The following observation could be made for concrete with SCM in a chloride environment:

- A lower climate impact per cubic meter of concrete due to lower clinker content.

- No significant difference between w/b ratios due to a compensation of an increase in concrete volume.

- A longer service life for bridges due to lower maintenance which results in a lower climate impact per year.

- Lower owner, user and societal costs in the case of bridge edge beams.

Addition of FA or GGBS in concrete is an efficient way to reduce the climate impact of the built environment. Also, by adapting performance based concrete cover thicknesses that include SCMs as well would greatly improve the quality of LCA and LCC of new projects and help pushing the industry towards a more sustainable development and an increased demand of existing and new SCMs.

The following directions for future research are suggested:

- Including an analysis of the reinforcement by keeping the cross-section area of the edge beam or pier constant while changing the amount and location of the reinforcement.

- A structural analysis could also be included in this type of study by adding the load bearing capacity to the functional unit. In that way different design options could be investigated.

- Including other durable materials such as ultra-high performance concrete and taking into consideration the possibility for a more slender structure.

- Investigating other deterioration mechanisms such as frost attack or the effect of multiple deterioration mechanisms.

- Adding LCC to the analysis.

\section{ACKNOWLEDGEMENT}

This study was financed by the Swedish Transport Administration and the CBI Foundation. The authors would also like to acknowledge Majid Solat Yavari for contributing with a bridge pier case. 
Nordic Concrete Research - Publ. No. NCR 58 - ISSUE 1 / 2018 - Article 5, pp. 77-93

\section{REFERENCES}

1. Trafikverket: "Klimatkrav i byggprojekt - ett viktigt steg mot klimatneutral infrastruktur," http://www.trafikverket.se/om-oss/nyheter/Nationellt/2016-02/klimatkrav-i-byggprojekt--ett-viktigt-steg-mot-klimatneutral-infrastruktur/ , accessed 2017. (In Swedish.)

2. Du G: "Life cycle assessment of bridges, model development and case studies," Doctoral thesis, KTH Royal Institute of Technology, Dept. of Civil \& Architectural Engineering, Stockholm, Sweden, 2015, 151 pp.

3. Müller H, Haist M \& Vogel M: “Assessment of the Sustainability Potential of Concrete and Concrete Structures Considering their Environmental Impact, Performance and Lifetime,” Construction and Building Materials, Vol. 67, 2014, pp 321-337.

4. Racutanu G: The Real Service Life of Swedish Road Bridges - A Case Study, Doctoral thesis. KTH Royal Institute of Technology, 2001.

5. Mattsson HÅ: "Integrated Bridge Maintenance - Evaluation of a pilot project and future perspectives,” Doctoral thesis. KTH Royal Institute of Technology, Dept. of Civil \& Architectural Engineering, Stockholm, Sweden, 2008.

6. Safi M: "Life-Cycle Costing: Applications and Implementations in Bridge Investment and Management,” Doctoral thesis, KTH Royal Institute of Technology, Dept. of Civil \& Architectural Engineering, Stockholm, Sweden, 2013.

7. Veganzones J, Sundquist H, Pettersson L \& Karoumi R: "Life-Cycle Cost analysis as a tool in the developing process for new bridge edge beam solutions," Structure and Infrastructure Engineering, Vol. 49, 2015, pp 1737-17746.

8. $\quad$ Tang L, Utgennant P \& Boubitas D: "Durability and Service Life Prediction of Reinforced Concrete Structures,” Journal of the Chinese Ceramic Society, Vol 43, 2015.

9. Tang L \& Löfgren I: "Evaluation of Durability of Concrete with Mineral Additions with regard to Chloride-Induced Corrosion,” Report No. 2016-4, Chalmers University of Technology, Dept. of Civil Engineering, Gothenburg, Sweden, 2016.

10. Streblow HH: "Mechanisms of pitting corrosion, Corrosion mechanism in theory in practice,” $2^{\text {nd }}$ edition (P. Marcus), Marcel Dekker Inc., New York, USA, 2002.

11. Arya C, Buenfeld NR \& Newman JB: "Factors Influencing chloride binding in concrete," Cement and Concrete Research, 20(2), 1990, pp 291-300.

12. Nilsson LO, Poulsen E, Sandberg P, Sorensen HE \& Klinghoffer O: “Chloride penetration into concrete - state of the art: Transport processes, corrosion initiation, test methods and prediction models,” HETEK Report No. 53, Danish Road Directorate, Copenhagen, Denmark, 1996.

13. Tuutti K: "Corrosion of steel in concrete," CBI research FO 4:82, Swedish Cement and Concrete Research Institute, Stockholm, Sweden, 1982.

14. Byfors $\mathrm{K}$ : "Influence of silica fume and flyash on chloride diffusion and $\mathrm{pH}$ values in cement paste”, Cement and Concrete Research, Vol. 17, 1987, pp. 115-130.

15. Angst U, Elsener B, Larsen CK \& Vennesland Ø: "Critical chloride content in reinforced concrete - a review,” Cement and Concrete Research, Vol. 39 (12), 2009, pp 1122-1138.

16. Khan MI: "Nanostructure and microstructure of cement concrete incorporating multicementitious composites," Transportation Research Record: Journal of the Transportation Research Board, No. 2141, Washington D.C., 2010, pp. 21-27.

17. Shi X \& Xie N: Fortune, K. \& Gong, J.: "Durability of steel reinforced concrete in chloride environments: An overview," Construction and Building Materials, 2012, pp 125-138.

18. Fib bulletin 34: “Model code for service life design”, fédération internationale du béton (fib), Lausanne, Switzerland, 2006. 
Nordic Concrete Research - Publ. No. NCR 58 - ISSUE 1 / 2018 - Article 5, pp. 77-93

19. SS-ISO 16204:2012: "Durability - Service life design of concrete structures," Swedish Standards Institute, Stockholm, Sweden, 2015.

20. CEN: "Concrete - Specification, performance, production and conformity EN 206:2013, European committee for standardization,” Brussels, Belgium, 2013.

21. SS 137003:2015: "Concrete - Application of SS-EN 206 in Sweden,” Swedish Standards Institute, Stockholm, Sweden 2015.

22. Boverket: ”Boverkets byggregler - EKS 10,” Boverket, Karlskrona, Sweden 2016. (In Swedish).

23. Tang L, Utgenannt P \& Boubitsas D: "Durability and Service Life Prediction of Reinforced Concrete Structures,” Journal of the Chinese Ceramics Society, 2015, pp 1408-1412.

24. Boubitsas D, Tang L \& Utgenannt P: "Chloride Ingress in Concrete Exposed to Marine Environment - Field data up to 20 years' exposure,” CBI Report to SBUF Project 12684, Swedish Cement and Concrete Research Institute, Stockholm, Sweden., 2014.

25. Löfgren I, Esping O \& Lindvall A: "The influence of carbonation and age on salt frost scaling of concrete with mineral addition,” Proceedings, International RILEM Conference on Materials, Technical University of Denmark, Lyngby, Denmark, 22-24 August 2016.

26. CEN: "Sustainability of Construction Works - Environmental Product Declarations Core Rules for the Product Category of Construction Products EN 15804, European committee for standardization,”, Brussels, Belgium, 2012.

27. Wernet G, Bauer C, Steubing B, Reinhard J, Moreno-Ruiz E \& Weidema B: "The ecoinvent database version 3 (part I): overview and methodology,”. International Journal of Life Cycle Assessment, [online] 21(9), pp.1218-1230. 2016. Available at: $<$ http://link.springer.com/10.1007/s11367-016-1087-8>.

28. Personal communication with Merox AB, 2012.

29. Personal communication with Thomas Concrete Group, 2016.

30. Svensk Fjärrvärme: Fjärrvärmestatistik, https://www.energiforetagen.se/statistik/fjarrvarmestatistik/tillford-energi/ , 2014.

31. Network for Transport Measures: NTMcalc - Calculation of Environmental Impact, https://www.transportmeasures.org/en/ , accessed 2016. 